\title{
Alterations in male rats following in utero exposure to betamethasone suggests changes in reproductive programming
}

\author{
Cibele S. Borges $^{\mathrm{a}, *}$, Ana Flávia M.G. Dias ${ }^{a}$, Josiane Lima Rosa ${ }^{a}$, Patricia V. Silva ${ }^{a}$, \\ Raquel F. Silva ${ }^{a}$, Aline L. Barros ${ }^{a}$, Marciana Sanabria ${ }^{a}$, Marina T. Guerra ${ }^{a}$, Mary Gregory ${ }^{b}$, \\ Daniel G. Cyr ${ }^{b}$, Wilma De G. Kempinas ${ }^{a}$ \\ a Department of Morphology, Institute of Biosciences, Univ Estadual Paulista-UNESP, Distrito de Rubião Junior s/n ${ }^{\circ}, 18618-970$ Botucatu, SP, Brazil \\ ${ }^{\mathrm{b}}$ Laboratory for Reproductive Toxicology, INRS-Institut Armand-Frappier, University of Quebec, 531 boulevard des Prairies, Laval, Québec, Canada, H7V 1B7
}

\section{A R T I C L E I N F O}

\section{Article history:}

Received 17 February 2016

Received in revised form 23 May 2016

Accepted 27 May 2016

Available online 28 May 2016

\section{Keywords:}

Betamethasone

Reproductive programming

Sexual development

Testis

Sertoli cell

Fertility

\begin{abstract}
A B S T R A C T
Antenatal betamethasone is used for accelerating fetal lung maturation for women at risk of preterm birth. Altered sperm parameters were reported in adult rats after intrauterine exposure to betamethasone. In this study, male rat offspring were assessed for reproductive development after dam exposure to betamethasone $(0.1 \mathrm{mg} / \mathrm{kg})$ or vehicle on Days $12,13,18$ and 19 of pregnancy. The treatment resulted in reduction in the offspring body weight, delay in preputial separation, decreased seminal vesicle weight, testosterone levels and fertility, and increased testicular weight. In the testis, morphologically abnormal seminiferous tubules were observed, characterized by an irregular cell distribution with Sertoli cell that were displaced towards the tubular lumen. These cells expressed both Connexin 43 (Cx43) and Proliferative Nuclear Cell Antigen (PCNA). In conclusion, intrauterine betamethasone treatment appears to promote reproductive programming and impairment of rat sexual development and fertility due to, at least in part, unusual testicular disorders.
\end{abstract}

(c) 2016 Elsevier Inc. All rights reserved.

\section{Introduction}

Betamethasone is used for pregnant women at risk for preterm birth, between 24 and 34 weeks of pregnancy [1-5]. In laboratory animals, studies have reported that this treatment may cause changes in brain and neuroendocrine functions, suppression of maternal and fetal adrenal function, as well as problems with male fertility [6-12].

During the treatment period, betamethasone promotes changes in intrauterine development that can impact fetal development resulting in persistent effects on the phenotype of the offspring $[13,14]$. In addition, fetal programming is most likely to result in permanent structural and physiological alterations, including risk of cardiovascular, metabolic and psychological diseases $[4,13]$.

Glucocorticoid administration to adult animals can decrease serum levels of testosterone $[15,16]$. This decrease in testosterone

\footnotetext{
* Corresponding author at: Laboratory of Biology and Toxicology of Reproduction and Development, Department of Morphology, Institute of Biosciences of Botucatu, UNESP-Univ Estadual Paulista, 18618-970, Botucatu, SP, Brazil.

E-mail address: cibelesantosborges@gmail.com (C.S. Borges).
}

appears to result from the inhibition of steroidogenic enzymes in Leydig cells [15-17].

During the second phase of intrauterine development, specifically between days $11-13$ and 18-19 of gestation, several changes in the morphology of the testis occur, e.g. an increase in Sertoli cell and germ cell proliferation, as well as an increase in testosterone levels [18-21]. Previous studies using this model reported alteration in semen quality of males exposed in utero to betamethasone [22]. The present study investigated the sexual development and fertility of male rats whose mothers were exposed to betamethasone during this period, with emphasis on the testicular development.

\section{Materials and methods}

\subsection{Animals and treatment}

Male (90 days old/300-350g) and female (90 days old/225-230g) Wistar rats were obtained from the Multidisciplinary Center for Biological Investigation, State University of Campinas and maintained under controlled conditions $\left(25^{\circ} \mathrm{C}\right.$, $30 \%$ air humidity, 12/12-h light/dark cycle) with food and water available ad libitum. Two nulliparous female rats were mated 
with one male, during the dark cycle of the photoperiod. The detection of sperm in the vaginal smear of rats in estrus was considered as gestational day 1 (GD1). Pregnant and lactating rats were maintained in individual cages. The experimental procedures used in this study were approved by the local Ethics Committee for the Use of Experimental Animals of the University of São Paulo State (protocol number 451-CEEA) in accordance with the Guide for the Care and Use of Laboratory Animals (National Institutes of Health). All surgical procedures were performed under ketaminexylazine anesthesia and euthanasia was performed by decapitation following $\mathrm{CO}_{2}$ asphyxiation.

\subsection{Experimental groups}

Pregnant female rats were randomly allocated into two experimental groups: control group $(n=11$; treated with saline (vehicle) alone) and treated group $(n=13 ; 0.1 \mathrm{mg} / \mathrm{kg}$; Betamethasone 21phosphate disodium diluted in vehicle; Sigma-Aldrich, St. Louis, MO). This dose was selected based on the dose used in clinic for maternal treatment and modified to rodents $[9,10]$. Rats received an intramuscular injection of vehicle or betamethasone on days 12 and 13 (period of germ cell and Sertoli cell proliferation), 18 and 19 (peak testosterone levels) of pregnancy. The injection protocol was based on the maternal corticosteroid therapy adapted by Souza et al. [11], which takes into account differences in the sexual differentiation in male fetuses $[9,10,23,24]$. During the treatment, the body weight and food consumption was monitored in pregnant females.

After birth, on post-natal day 1 (PND1), the number of pups per litter was randomized and redistributed in order to have 8 pups (4 males and 4 females) per lactating female. Rats were weaned at PND21 and housed in separate cages ( $n=4$ males per cage). Male rats $(n=2-3)$ from each litter were used in order to prevent potential variation due to litter effects, as described below.

\subsection{External examination at puberty}

Rats pups were weighed and anogenital distance measured at PND1 in four male rats per litter ( $n=11-13$ per group). The onset of puberty was determined by manual retraction of the prepuce [25].

\subsection{Organ weights}

On PND 45 ( $n=10 /$ group) and PND110 ( $n=5$ /group), rats were weighed and euthanized. After euthanization, blood was collected (9:00 and 11:30 AM) and the right testis, epididymis, seminal vesicle (full and empty, without the coagulating gland), and ventral prostate were dissected and weighed. The left testes were fixed for histology and immunohistochemistry.

\subsection{Serum hormonal levels}

Blood samples were allowed to coagulate and the serum obtained by centrifugation ( $2400 \mathrm{rpm}$ ) for $20 \mathrm{~min}$ at $4{ }^{\circ} \mathrm{C}$ and stored at $-20^{\circ} \mathrm{C}$. Serum testosterone, FSH and LH levels were determined by radioimmunoassay. Testosterone levels were measured using the Coat-A-Count ${ }^{\circledR}$ assay (Diagnostics Products Corporation, Los Angeles, USA) while LH and FSH were measured using specific kits supplied by the National Institute of Arthritis, Diabetes and Kidney Diseases (NIADDK). All samples were measured within the same assay to avoid the inter-assay errors. Intra-assay variabilities were $3.4 \%$ for $\mathrm{LH}, 2.8 \%$ for $\mathrm{FSH}$, and $4 \%$ for testosterone.

\subsection{Histological analyses}

Left testes were fixed by immersion in Bouin's fixative, dehydrated, and embedded in Paraplast Plus ${ }^{\circledR}$ (P3683, Sigma-Aldrich). Tissues were sectioned $(5 \mu \mathrm{m})$, mounted on a glass slide and stained with hematoxylin and eosin (HE) to evaluate testicular morphology. Sections destined for immunohistochemistry were mounted on silanized glass slides and stored at room temperature. Histopathology was analyzed in a blind assay using a Zeiss microscope (model Scope A1-Axio) mounted with a digital camera and analysis software (ZeissAxio Vision, version 4.7.2).

Three non-serial testicular sections of $50 \mu \mathrm{m}$ apart were taken for each animal in order to evaluate 100 seminiferous tubules. Seminiferous tubules were classified as being either normal or abnormal. The interstitium and peritubular myoid cells were also examined, as were the general morphology of the Leydig cells and the appearance of blood vessels [26].

The diameter of the seminiferous tubules and thickness of germinal epithelium was evaluated in 10 sections of seminiferous tubules per animal ( $\mathrm{n}=5$ per group) in tubules at stage IX of spermatogenesis. This was done using a Leica DMLB microscope with a magnification of 200X and analyzed with the Leica Q-Win software (version 3).

In order to evaluate the degree of maturation of the seminiferous epithelium, 100 cross-sections of seminiferous tubules per animal ( $n=5$ per group) were randomly evaluated by assigning values according to the abundance of mature germ cells in the epithelium [27]. The following scale was used: degree 1 (I): young spermatids with rounded nucleus (stages $1-8$ of the cycle of the seminiferous epithelium); degree 2 (II): spermatids in maturation phase, with ovoid or elongated nucleus (stages 9-14); degree 3 (III): spermatids in maturation phase, with elongated nucleus (stages 15-18); degree 4 (IV): mature spermatids (stage 19) in small numbers; degree $5(\mathrm{~V})$ : mature spermatids (stage 19) in average numbers; degree 6 (VI): mature spermatids (stage 19) in high abundance. Each symbol means the numbers of tubules in this degree. The "average degree" was determined using the following mathematical formula: Average degree $=[(\mathrm{I} \times 1)+(\mathrm{II} \times 2)+(\mathrm{III} \times 3)+(\mathrm{IV} \times 4)+(\mathrm{V} \times 5)+(\mathrm{VI} \times 6)] / 100$.

In order to evaluate the dynamics of spermatogenesis, the relative frequency of stages was estimated: I-VI (two generations of spermatids), VII-VIII (mature spermatids), IX-XIII (only one generation of spermatids), XIV (secondary spermatocyte) in 100 cross-sections of seminiferous tubules per animal. The relative frequency of stages estimates the rate or duration of spermatogenic process [28].

Furthermore, the number of Sertoli cell nuclei and the volume of Leydig cells also determined. Sertoli cell nuclei were determined in histological sections in 20 seminiferous tubules per rat testis in stage VII of spermatogenesis. The nuclear volume of Leydig cells was measured by randomly selecting 50 circular or elliptical cells, their diameters (D) were measured and the volume was obtained using the formula: $\mathrm{V}=[\mathrm{D} \times \pi\} / 6$.

\subsection{Immunohistochemistry for CX43 and PCNA in the testis}

Histological sections ( $n=5$ animals per group) were deparaffinized and hydrated in graded ethanol and washed in TBST (Tris-Buffered Saline, 0.1\% Tween-20). Sections were then subjected to antigen retrieval in citrate buffer $(0.01 \mathrm{M}, \mathrm{pH} 6.0)$ and heated in a microwave. Slides were washed in $\mathrm{ddH}_{2} \mathrm{O}$, followed by hydrogen peroxide (3\%) for $15 \mathrm{~min}$, tap water $(5 \mathrm{~min})$, and then incubated in blocking solution (TBST, 5\% BSA) for $1 \mathrm{~h}$ at $37^{\circ} \mathrm{C}$ in a humidified chamber. Sections were then incubated with primary antisera. Sections were incubated overnight with antiCX43 $(0.625 \mu \mathrm{g} / \mathrm{ml}$, C-6219; Sigma-Aldrich); or with anti-PCNA 
(4 $\mu \mathrm{g} / \mathrm{ml}$, SC-56/PC-10; Santa Cruz Biotechnology). Sections were then washed 3 times in TBST and incubated with the appropriate secondary antibody for $1 \mathrm{~h}$ at $37^{\circ} \mathrm{C}$ (for Cx43: goat anti-rabbit HRP ( $1 \mu \mathrm{g} / \mathrm{ml}$, C\# 6721;Abcam); for PCNA: goat anti-mouse HRP $(1.6 \mu \mathrm{g} / \mathrm{ml} \mathrm{SC}-2005$; Santa Cruz Biotechnology)). Sections were subsequently washed with TBST and incubated with diaminobenzidine ( $0.5 \mathrm{mg} / \mathrm{ml}$, Sigma-Aldrich) for $15 \mathrm{~min}$, rinsed in tap water and counterstained with methylene blue for $5 \mathrm{~min}$. Negative control sections did not receive primary antibody.

\subsection{Fertility evaluation after natural mating}

At PND90, one male rat per litter ( $\mathrm{n}=11-13$ /group) was placed in a cage alone for $5 \mathrm{~min}$ prior to the introduction of a sexually receptive female ( 70 days old) and the paired animals were kept together for $3 \mathrm{~h}$ after the first ejaculation. Females were removed and vaginal smears were collected to confirm whether or not insemination occurred. Females naturally inseminated by rats from the control and treated groups were euthanized 20 days after mating to assess male fertility. A median laparotomy was done and the uterus and ovaries were collected. The numbers of corpora lutea, implants, resorptions, as well as the number of live and dead fetuses was determined. From these results the following parameters were calculated: Pregnancy rate or index: (number of females achieving a pregnancy/number of potentially fertile females that were mated) $\times 100$; fertility potential (efficiency of implantation): (implantation sites/corpora lutea) $\times 100$; rate of pre-implantation loss: [(number of corpora lutea - number of implantations)/number of corpora lutea] $\times 100$; and rate of postimplantation loss: [(number of implantations - number of live fetuses)/number of implantations] $\times 100$.

\subsection{Statistical analysis}

Data are presented as mean \pm standard error of mean (SEM) or median and interquartile range. A Student $T$-test was used for comparison of parametric variables. Non-parametric data were compared using a Mann-Whitney test. Differences were considered significant when $\mathrm{p} \leq 0.05$. Statistical analyses were performed using the GraphPad InStat software (version 5).

\section{Results}

Prenatal betamethasone treatment resulted in a significant reduction in food intake (Fig. 1A) and weight gain of the dams (Fig. 1B) as well as in the weight of the male offspring at PND 1 (Fig. 1C). However, the relative anogenital distance was similar between control and betamethasone-treated group ( $2.23 \pm 0.04$ for control vs $2.30 \pm 0.02$ for betamethasone group). After weaning, the differences in body weight between groups did not persist (data not shown).

Preputial separation, which is the first sign of puberty, was delayed in the betamethasone offspring (Fig. 1D). These animals had lower levels of serum testosterone levels at PND45. However, at PND110 there were no differences in testosterone levels. Interestingly, there was a significant increase in LH levels which extended into adulthood (Fig. 2).

Testicular weights were significantly higher in the betamethasone group at both PND45 and 110. Furthermore, ventral prostate weights were also significantly higher, but only at PND110. In contrast, seminal vesicle weights were significantly lower at PND45, when testosterone levels were lower, but not at PND110 (Table 1).

The degree of maturation of the seminiferous epithelium at PND 45 was significantly different between the treated and control group, thus, the betamethasone group showed a delay in the maturation of the germ cells (Table 2). In the same way, the spermatogenesis showed a significant decrease in the percentage of seminiferous tubules in VII-VIII stages (Table 2).

Morphometric analysis of testis indicated a decrease in the diameter of the seminiferous tubules in both ages (Table 2). Even though the height of epithelium was smaller in the treated group, this effect was not statistically significant (PND45, $\mathrm{p}=0.06$; PND110, $\mathrm{p}=0.17$ ). The number of the Sertoli cell nuclei in stage VII of spermatogenesis and the volume of Leydig cells were similar between the groups (Table 2).

Testicular histopathology indicated that approximately $20 \%$ of tubules from betamethasone-treated rats showed abnormalities at both ages (Table 2). Of those, $6 \%$ of tubules in PND45 and 14\% in PND110 displayed Sertoli cell nuclei migration towards the lumen of the tubule, while this abnormality was noted in two tubules of a single control rat in PND110 (Fig. 3). It is important to note that in these seminiferous tubules, spermatogenesis is active and there are no apoptotic cells observed (Fig. 3D and $\mathrm{H}$ ). The mis-localized germ and Sertoli cell nuclei seem to maintain the same organization as the normal tubule, and the cellular organization of Sertoli and germ cells appears to be maintained in the displaced, or invaginated, Sertoli cells.

In the seminiferous tubules of control animals, Sertoli cells were identified at the basal region of the seminiferous tubule, and the blood-testis barrier appeared morphologically intact. Cx43 was localized to the base of the tubules between adjacent Sertoli cell nuclei in the area of the blood-testis barrier. In the betamethasone group, Cx43 immunostaining was less intense; however, in the tubules in which Sertoli cell nuclei migration was altered, Cx43 immunostaining remained localized between displaced Sertoli cells (Fig. 4). In the seminiferous tubules from control rats, PCNA was localized to nuclei of spermatogonia located near the base of the seminiferous tubule. Likewise, PCNA remained localized to the nuclei of spermatogonia in betamethasone-treated rats in which Sertoli cells and spermatogonia had migrated towards the lumen of the tubule (Fig. 5). This indicated that not only were the Sertoli cells mis-localized, but that the germ cells remained associated with the displaced Sertoli cells.

There was a significant reduction in the fertility potential, as well as an increase in pre-implantation loss (Table 3). Interestingly, body weights of fetuses from treated males were significantly lower as compared to control animals, suggesting a potential transgenerational effect (Table 3).

\section{Discussion}

At the end of pregnancy, an increase in plasma cortisol levels is essential for the final development and differentiation of fetal organs, especially the lungs [29]. These final stages of maturation can be induced with the use of synthetic glucocorticoids, as in the case of preterm delivery, thereby reducing neonatal mortality [30]. Betamethasone, a potent synthetic glucocorticoid, is generally the drug of choice for this antenatal therapy [4]. However, animal studies have shown that fetal exposure to synthetic glucocorticoids promotes an increased incidence of behavioral, metabolic and endocrine issues in the long-term $[8,12,29]$. Previous studies in rats have shown that betamethasone treatment can result in decreased testosterone levels and altered sperm parameters of male offspring $[9,10]$. Our results demonstrated that betamethasone treatment during the sensitive window of development caused a delay in the onset of puberty in male rat offspring, possibly resulting from testicular alterations, which persisted into adulthood and which negatively impacted male fertility.

Preputial separation was delayed in rats exposed to betamethasone, suggesting a delay in the onset of puberty [31]. In these 
A

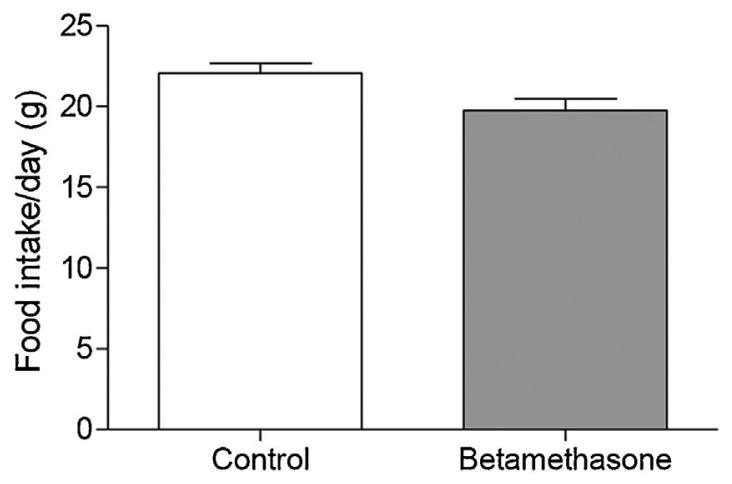

C

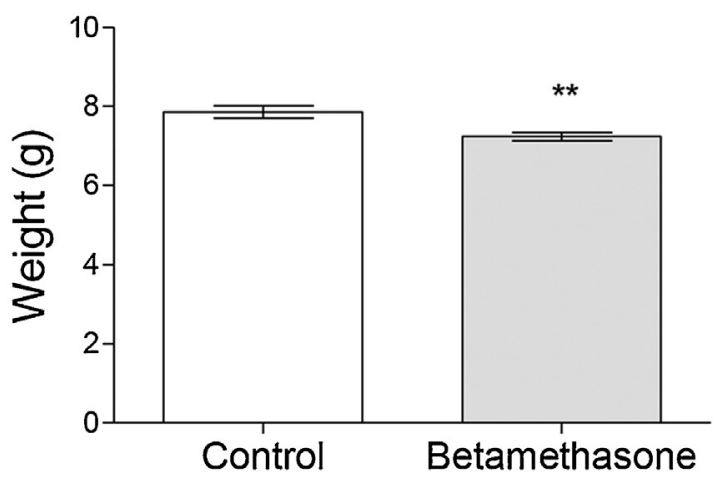

B

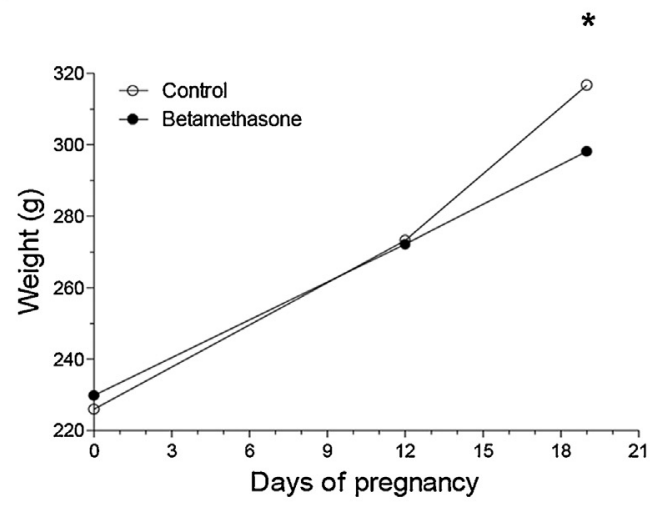

D

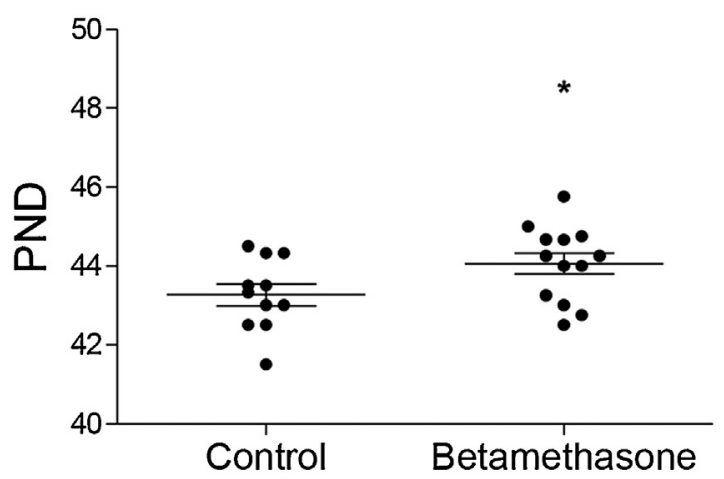

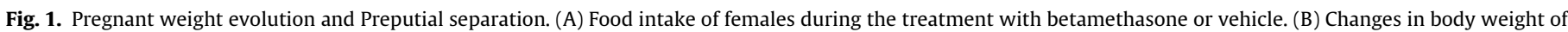

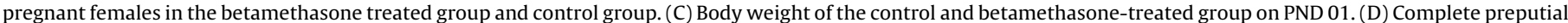

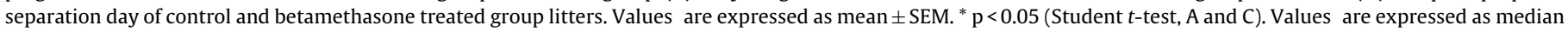
and interquartile ranges (first and third) ${ }^{*} \mathrm{p}<0.05$ (Mann-Whitney test, B).

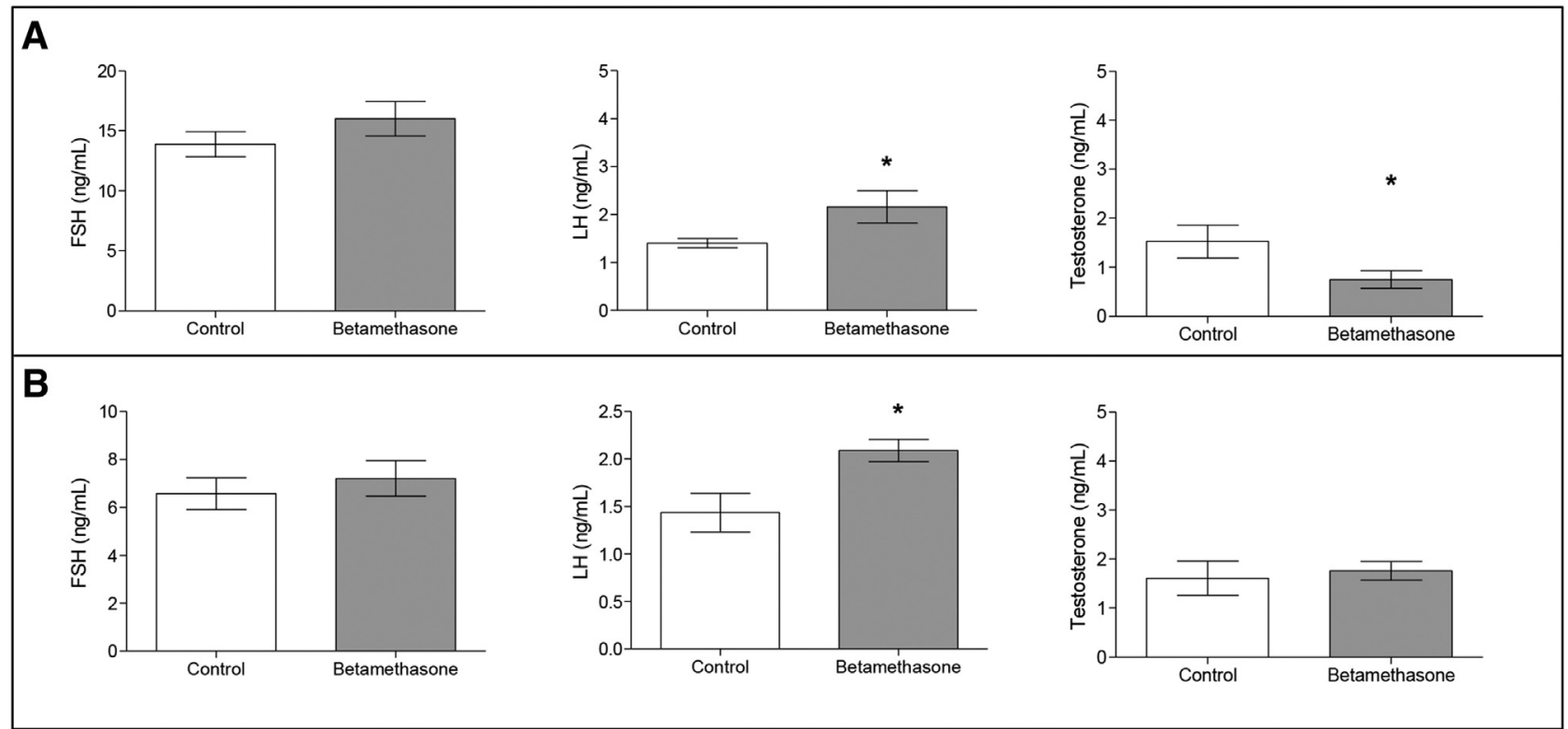

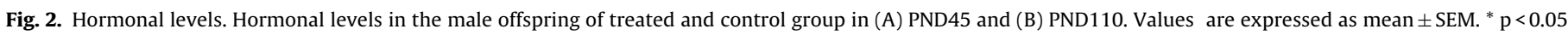
(Student's $t$-test).

animals, a delay in the maturation degree of germ cells in PND45 and a significant decrease in serum testosterone levels were also observed. Glucocorticoid exposure during intrauterine development at gestational days 12-19 interferes directly with circulating testosterone levels and this change may extend throughout development $[9,10,15-18]$. Thus, our present data confirm the impact of betamethasone on testosterone levels until puberty and its impact on spermatogenesis. However, testosterone levels in the treated 
Table 1

Reproductive parameters.

\begin{tabular}{|c|c|c|c|c|}
\hline \multirow[t]{3}{*}{ Parameters } & \multicolumn{4}{|c|}{ Experimental groups } \\
\hline & \multicolumn{2}{|l|}{ PND45 } & \multicolumn{2}{|l|}{ PND110 } \\
\hline & Control $(n=10)$ & Betamethasone $(\mathrm{n}=10)$ & Control $(n=05)$ & Betamethasone $(\mathrm{n}=05$ \\
\hline Final body (g) & $224.30 \pm 2.76$ & $225.20 \pm 3.33$ & $450.20 \pm 11.37$ & $432.30 \pm 14.15$ \\
\hline Testis (g) & $1.13 \pm 0.023$ & $1.19 \pm 0.017^{*}$ & $1.75 \pm 0.05$ & $1.87 \pm 0.01^{*}$ \\
\hline Epididymis (mg) & $120.70 \pm 3.36$ & $130.70 \pm 5.69$ & $539.10 \pm 22.79$ & $564.60 \pm 14.06$ \\
\hline Ventral prostate (mg) & $89.02 \pm 3.90$ & $97.36 \pm 6.07$ & $359.20 \pm 15.00$ & $426.30 \pm 12.13^{* *}$ \\
\hline Seminal vesicle (mg) & $83.36 \pm 4.048$ & $69.78 \pm 3.93^{*}$ & $1289.00 \pm 48.52$ & $1117.00 \pm 102.70$ \\
\hline Testis (g/100 g) & $0.51 \pm 0.01$ & $0.53 \pm 0.02^{*}$ & $0.39 \pm 0.01$ & $0.43 \pm 0.01^{*}$ \\
\hline Epididymis (mg/100 g) & $54.11 \pm 1.58$ & $57.94 \pm 2.13$ & $120.10 \pm 6.17$ & $131.30 \pm 5.84$ \\
\hline Ventral prostate $(\mathrm{mg} / 100 \mathrm{~g})$ & $40.03 \pm 2.09$ & $43.30 \pm 2.76$ & $79.85 \pm 3.29$ & $99.15 \pm 4.96^{* *}$ \\
\hline Seminal vesicle $(\mathrm{mg} / 100 \mathrm{~g})$ & $37.48 \pm 2.06$ & $31.24 \pm 1.69^{*}$ & $287.30 \pm 13.68$ & $260.40 \pm 27.09$ \\
\hline
\end{tabular}

Values expressed as mean \pm SEM. $T$-Student test.

${ }^{*} \mathrm{p} \leq 0.05$.

p $\leq 0.01$

Table 2

Histology and morphometric assay ( $n=05 /$ group).

\begin{tabular}{|c|c|c|}
\hline Parameters & Control & Betamethasone \\
\hline${ }^{a}$ Normal tubules PND45 (\%) & $95.00(90.00-96.00)$ & $83.00(81.50-88.00)^{*}$ \\
\hline${ }^{\mathrm{b}}$ Closed tubules PND45 (\%) & 0.0 & $6.0^{* * *}$ \\
\hline${ }^{a}$ Normal tubules PND110 (\%) & $95.00(94.50-98.50)$ & $80.00(77.50-91.00)^{* *}$ \\
\hline${ }^{\mathrm{b}}$ Closed tubules PND110 (\%) & 0.8 & $14.0^{* * *}$ \\
\hline${ }^{\mathrm{c}}$ Degree of maturation cells $(1-5)$ & $3.16(2.95-3.23)$ & $2.70(2.64-2.86)^{* *}$ \\
\hline \multicolumn{3}{|l|}{${ }^{\mathrm{c}}$ Dynamics of spermatogenesis } \\
\hline I-VI $(\%)$ & $32.00(28.00-36.00)$ & $37.00(35.00-39.00)$ \\
\hline VII-VIII (\%) & $29.00(27.00-32.50)$ & $19.00(12.00-22.50)^{* *}$ \\
\hline IX-XIII (\%) & $33.00(29.50-35.50)$ & $36.00(34.00-41.00)$ \\
\hline XIV $(\%)$ & $6.00(4.50-8.00)$ & $8.00(7.00-10.00)$ \\
\hline${ }^{\mathrm{c}}$ Tubular diameter PND45 $(\mu \mathrm{m})$ & $265.10 \pm 8.34$ & $241.10 \pm 5.72^{*}$ \\
\hline${ }^{c}$ Epithelium high PND45 $(\mu \mathrm{m})$ & $80.93 \pm 2.56$ & $75.10 \pm 1.11$ \\
\hline${ }^{\mathrm{c}}$ Tubular diameter PND110 $(\mu \mathrm{m})$ & $279.40 \pm 12.18$ & $253.70 \pm 3.54^{*}$ \\
\hline${ }^{\mathrm{c} E p}$ ithelium high DP110 $(\mu \mathrm{m})$ & $90.12 \pm 5.76$ & $83.41 \pm 1.14$ \\
\hline a Sertoli cell nuclei number PND110 (n) & $16.46 \pm 0.84$ & $16.82 \pm 1.41$ \\
\hline${ }^{a}$ Leydig cells volume PND110 $\left(\mu \mathrm{m}^{3}\right)$ & $122.20 \pm 16.40$ & $98.91 \pm 6.92$ \\
\hline
\end{tabular}

a Values expressed as median and interquartile intervals (Mann-Whitney test).

b Values are expressed as a percentage (Chi-Square test).

c Values expressed as mean \pm SEM ( $T$-Student test).

${ }^{*} \mathrm{p} \leq 0.05$.

${ }^{* *} \mathrm{p} \leq 0.01$.

*** $\mathrm{p} \leq 0.001$.

Table 3

Fertility after natural mating.

\begin{tabular}{|c|c|c|}
\hline Parameters & Control $(n=11)$ & Betamethasone $(\mathrm{n}=11)$ \\
\hline Pregnancy rate (\%) & 90.90 & 76.92 \\
\hline${ }^{a}$ Fertility potential (\%) & $92.58(85.00-100.00)$ & $78.57(72.50-81.53)^{*}$ \\
\hline apre- implantation loss (\%) & $0.00(7.42-15.00)$ & $21.43(8.17-27.50)^{*}$ \\
\hline${ }^{a}$ Post- implantation loss (\%) & $8.33(7.69-17.50)$ & $8.39(0.00-11.36)$ \\
\hline${ }^{\mathrm{b}}$ Body weight of dams ( $\mathrm{g}$ ) & $336.90 \pm 8.55$ & $338.00 \pm 10.78$ \\
\hline${ }^{\mathrm{b}}$ Uterus weight with fetuses ( $\mathrm{g}$ ) & $52.72 \pm 3.85$ & $48.05 \pm 2.38$ \\
\hline${ }^{\mathrm{b}}$ Corpora lutea number & $12.70 \pm 0.72$ & $14.80 \pm 1.03$ \\
\hline${ }^{\mathrm{b}}$ Implantation number & $11.60 \pm 0.82$ & $11.50 \pm 0.43$ \\
\hline${ }^{\mathrm{b}}$ Resorption number & $1.20 \pm 0.25$ & $1.00 \pm 0.30$ \\
\hline${ }^{\mathrm{b}}$ Fetus weight $(\mathrm{g})$ & $3.12 \pm 0.08$ & $2.62 \pm 0.19^{*}$ \\
\hline${ }^{b}$ Placental weight (g) & $0.50 \pm 0.02$ & $0.47 \pm 0.01$ \\
\hline
\end{tabular}

a Values expressed as median and interquartile intervals (Mann-Whitney test).

b Values expressed as mean \pm SEM. (Student's $t$-test).

* $\mathrm{p}<0.05$.

rats recovered to control levels by adulthood. These results parallel Leydig cell volumes, which are similar to controls at this age. In contrast, Piffer et al. [9] reported that testosterone levels in betamethasone-treated rats were significantly lower through adulthood. The reason for these differences is unknown, but the increase in LH levels in the present data may have promoted a recovery in testosterone levels.
The significant reduction in litter weights observed in the betamethasone group may have contributed to the delayed onset of puberty, since lower birth weight, one of the first signs of altered fetal programming [32], also observed after betamethasone treatment, is correlated to the initiation of puberty $[9,10,33]$. However, anogenital distance, often used as an indicator of feminization [34], was not significantly different between control and treated rats. 


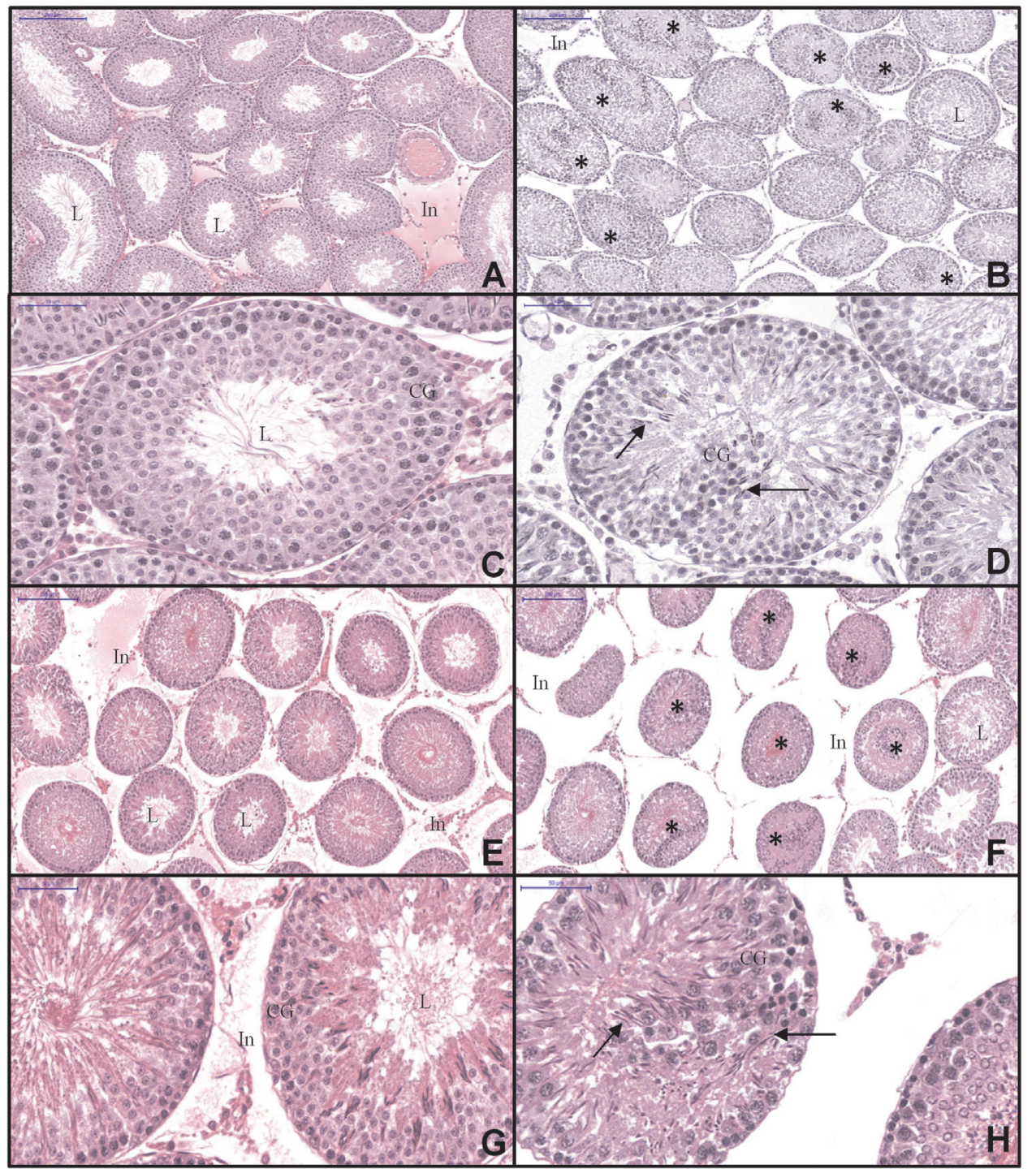

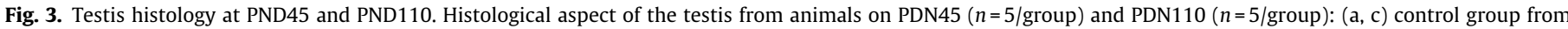

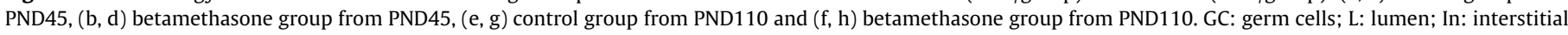

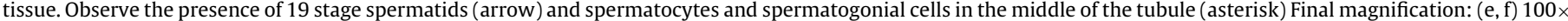
(a, b) $200 \times$ and (c, d,g,h) $400 \times$.

In addition to the decreased offspring weight, there was also a decrease in the body weight of mothers during betamethasonetreatment. This reduction appears to be, at least in part, associated with decreased food intake. Franko et al. [35] and Woods [36] observed similar results in rats treated with glucocorticoids. The seminal vesicles and ventral prostate are androgen-dependent organs, and their weight generally reflect changes in bioavailable androgens [24,37-39]. While the weights of seminal vesicles appear to be correlated with circulating levels of androgens, betamethasone appears to exert a specific effect on the ventral prostate that is independent of circulating androgen levels. This is reflected by the significantly higher ventral prostate weight observed in treated adults when androgen levels are similar to those in control rats. While androgens regulate prostate weights, toxicants such as tributyltin have been reported to alter prostate weights independent of circulating androgens [40]. Indeed, Zhao et al. [41] demonstrated androgen-independent growth of prostate cells mediated by glucocorticoids. Thus, our data would suggest that in utero betamethasone can exert an effect on the development of the prostate resulting in increased ventral prostate weight in adults. Additional studies will be necessary to understand the mechanisms responsible for this.

Betamethasone-treatment also resulted in an increase in testis weight at both PND45 and 110. Testicular histology in the betamethasone group showed a different pattern of Sertoli and germ cell distribution. Our data indicate that $14 \%$ of the seminiferous tubules displayed disrupted germ cell organization and distribution with abnormal migration of Sertoli and germ cells toward the lumen of the seminiferous tubule in adult animals as well as in $6 \%$ of the tubules of pubertal animals. Sasso-Cerri and Cerri [42] reported that the antihistamine cimetidine, which exerts anti-androgenic effects, altered the organization of seminiferous tubules, and it is possible to observe the Sertoli cell nuclei and germ cells localizing toward the lumen of the tubule. In the present study, a similar pattern was observed in which betamethasone resulted in mis-localized Sertoli cells.

In order to determine whether or not the Sertoli cells that appear to migrate towards the lumen of the seminiferous tubules maintained their interaction with adjacent cells, immunolocalization of the gap junction protein $\mathrm{Cx} 43$ was performed. $\mathrm{Cx} 43$ has been shown 


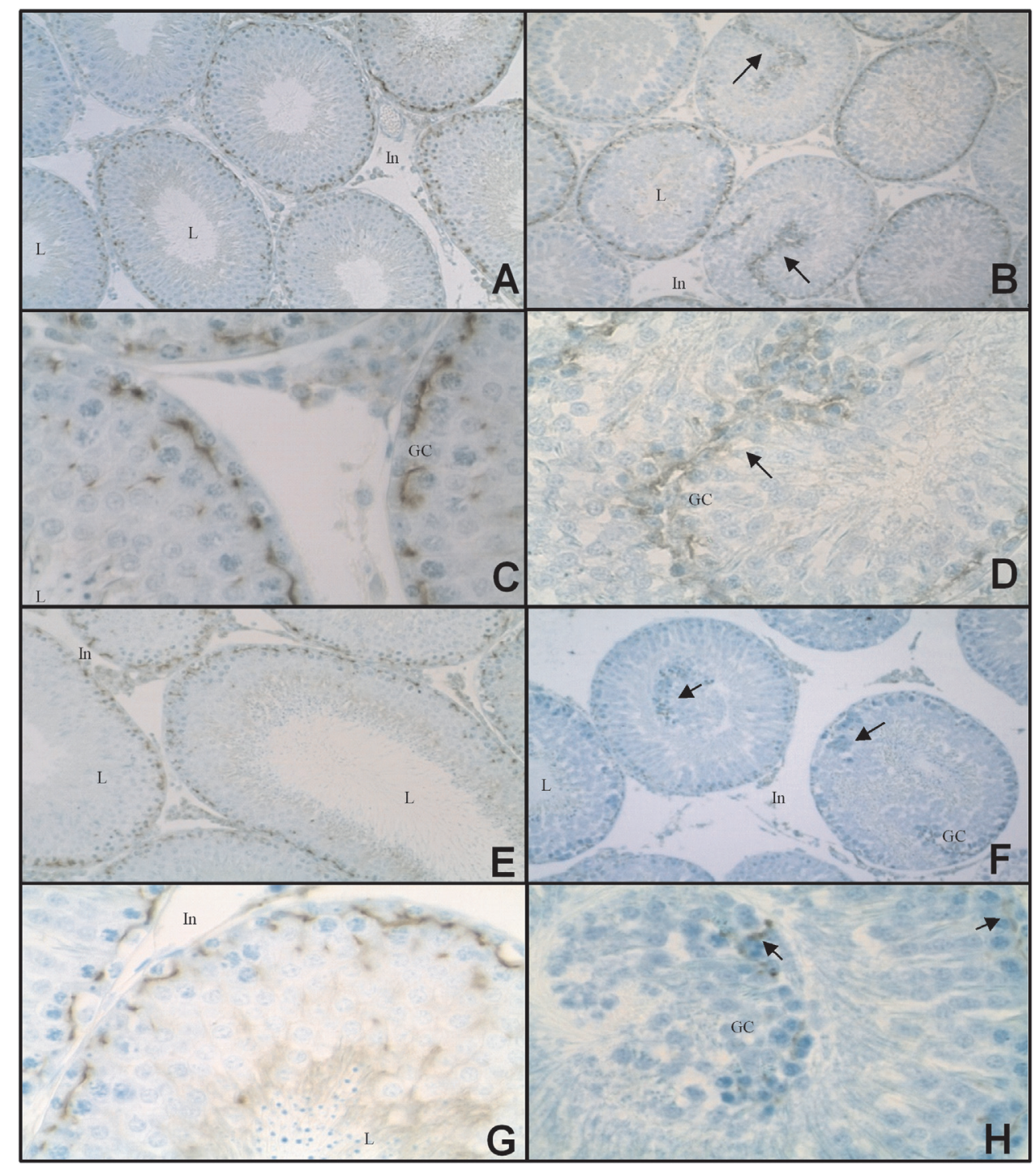

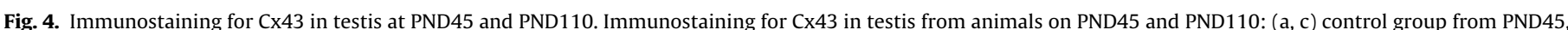

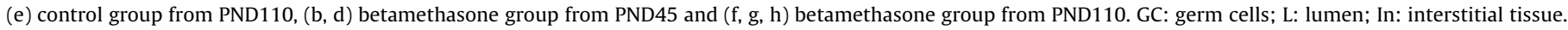

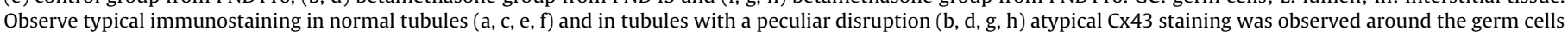

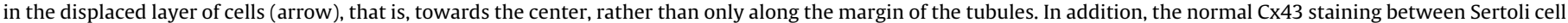
nuclei and marginal germ cells was faint or absent (b). Final magnification: (a, b, e, f, g) 160× and (c, d, h) 640×.

to be expressed between adjacent Sertoli cell nuclei in the testis and is necessary for Sertoli cell nuclei and germ cell migration during development and spermatogenesis in the adult [43-47]. Cx43 has also been implicated in the organization of the blood-testis barrier and intercellular communication between Sertoli cell nuclei and between Sertoli and germ cells $[44,45,48]$. In the present study, Cx43 immunostaining appeared to be less intense in betamethasone group. Alterations in the expression of $\mathrm{Cx} 43$ in the testis have been shown to result in alteration in spermatogenesis and increased germ cell apoptosis $[47,49]$. In tubules in which the Sertoli cell nuclei appear to show invagination towards the lumen, there is less intense $\mathrm{Cx} 43$ staining, and this appeared to remain localized to gap junctions between adjacent Sertoli cell nuclei. These results would suggest that, at least in part, the treatment with betamethasone impacts normal expression of $\mathrm{Cx} 43$, which may lead to problems in spermatogenesis.

PCNA immunolocalization was done to determine the proliferative capacity of the cells [50,51]. In the testis, the staining was primarily associated with spermatogonia with no detectable immunostaining in spermatids [52]. PCNA-positive spermatogo- nia were distributed around the tubules in both controls and betamethasone-treated animals. PCNA immunostaining was also observed in cells present at the base of the displaced Sertoli cell nuclei, suggesting that these remained associated with Sertoli cell nuclei. This would support the notion that the Sertoli cells maintained many of their normal function, including the interaction with developing germ cells, despite the loss of interaction with the basement membrane. However, in these tubules, the spermatogenesis seems to be compromised, since there is no lumen in these seminiferous tubules.

Morphometric analysis of testes revealed that the tubular diameters of the seminiferous tubules at both ages were significantly reduced in the betamethasone-group. Tubular diameter is a sensitive indicator of spermatogenic capacity of several species of animals [53,54]. It is possible that the betamethasone treatment reduced sperm production. Piffer et al. [9] demonstrated a similar reduction in tubule diameter in rats treated with betamethasone. Furthermore, the reduction in the frequency of stage VII-VIII tubules at PND110, may be correlated to the diameter of the tubules, since these are in the final stages of the spermatogene- 


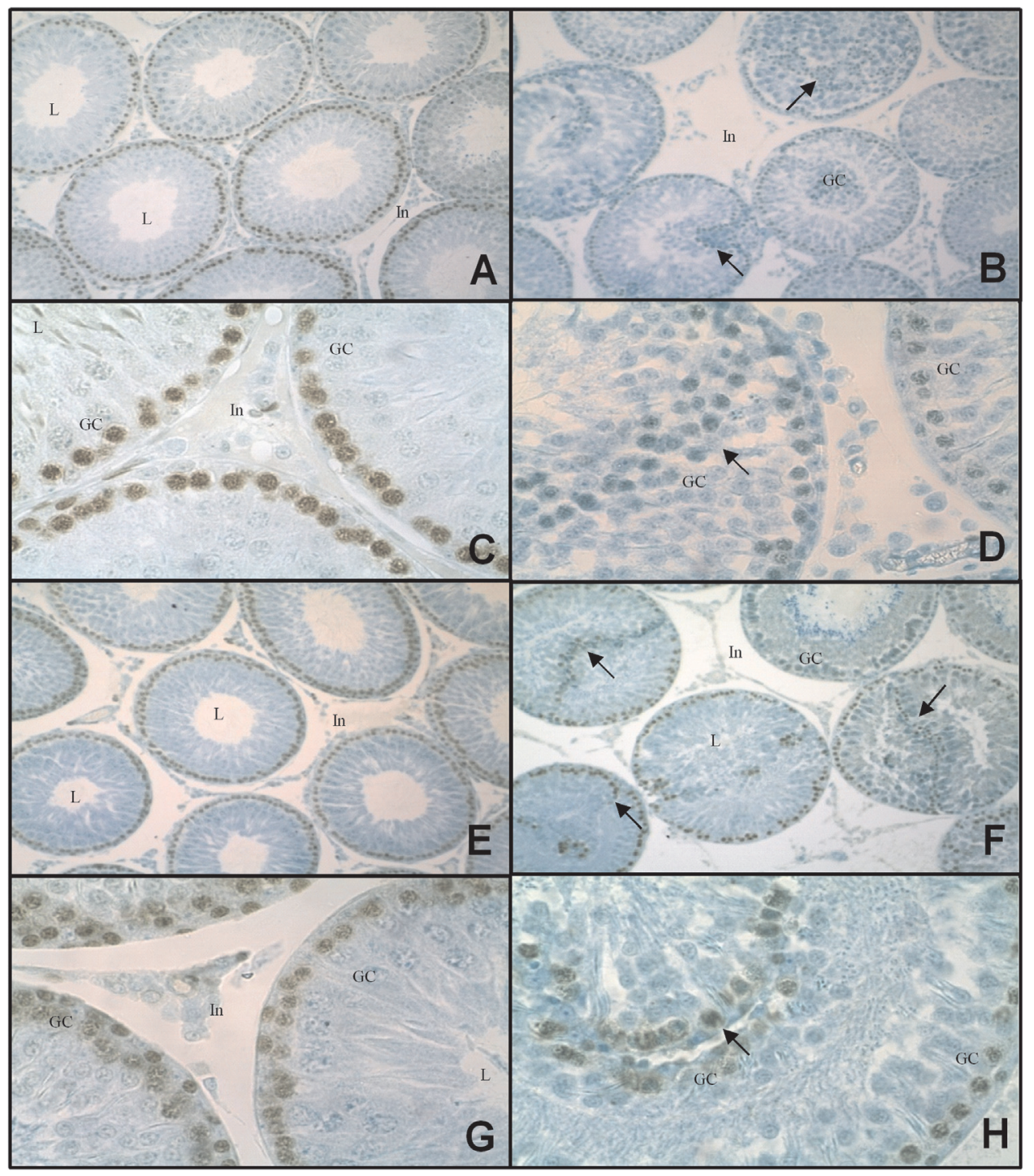

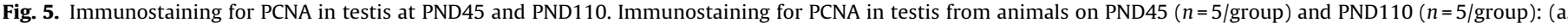

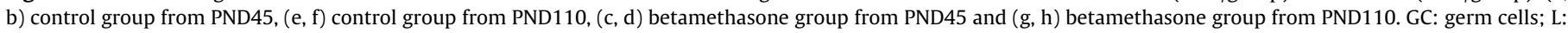

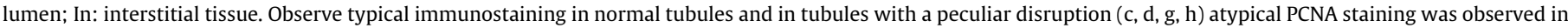
germ cells in the displaced layer of cells (arrow). Final magnification: (a, c, e, g) 160× and (b, d, f, h) 640×.

sis [54]. Thus, the histological alterations observed appears to be promoted by a restriction in the size of the tubule which forces the invagination of the cells, as there appears to be no changes in the number of Sertoli cells in stage VII of spermatogenesis.

In order to determine whether or not the changes observed in this study altered fertility of the male rats, animals were mated. Our results indicated that the fertility potential of betamethasonetreated rats was significantly reduced and that this could result from fewer sperm being ejaculated or from a reduction in sperm quality, as previously observed by Borges et al. [22]. Piffer et al., [9] also reported that betamethasone-treatment resulted in increased post-implantation loss. These observations indicate that betamethasone-induced alterations in the testis alter sperm production and quality, leading to decreased fertility and decreased production of viable offspring. Considering that rodents have a higher fertility potential than humans [55], our results suggest that betamethasone may have a greater impact on human reproduction.

In conclusion, the administration of betamethasone during a critical period of pregnancy in rats promotes reproductive reprogramming, leading to impairment of sexual development and fertility due to, at least in part, an unusual testicular disorder. These results raise concern for children exposed to betamethasone antenatally.

\section{Conflict of interest}

The authors declare that there are no conflicts of interest.

\section{Acknowledgments}

This work was supported by FAPESP-The State of São Paulo Research Foundation [Grant numbers 2012/25350-1 and 2013/26557-1]; CNPq-National Council for Scientific and Technological Development [Grant number 308842/2013-8]; FQRNT-The Fonds de recherche du Québec-Nature et technologies and The Natural Sciences Research Council of Canada [Grant number 155065-06]. The authors are grateful to Dr. Janete Anselmo-Franci and to Ruither de Oliveira Gomes Carolino of the Department of Morphology, Stomatology and Physiology, Dental School of Ribeirão Preto, University of São Paulo-USP, for the collaboration with the hormonal assays, to Julie Dufresne of INRS-Institut 
Armand-Frappier, for their assistance. José Eduardo Bozano, assisting academic support, of the Department of Morphology, Institute of Biosciences, São Paulo State University-UNESP, is also thanked for his assistance.

\section{Appendix A. Supplementary data}

Supplementary data associated with this article can be found, in the online version, at http://dx.doi.org/10.1016/j.reprotox.2016. 05.021 .

\section{References}

[1] M.C. Audette, J.R. Challis, R.L. Jones, C.P. Sibley, S.G. Matthews, Synthetic glucocorticoid reduces human placental system a transport in women treated with antenatal therapy, J. Clin. Endocrinol. Metab. 99 (11) (2014) E2226-33.

[2] P.A. Crowley, Antenatal corticosteroid therapy: a meta-analysis of the randomized trials 1972-1994, Am. J. Obstet. Gynecol. 173 (1) (1995) 322-335.

[3] A.H. Jobe, R.F. Soll, Choice and dose of corticosteroid for antenatal treatments, Am. J. Obstet. Gynecol. 190 (4) (2004) 878-881.

[4] V.G. Moisiadis, S.G. Matthews, Glucocorticoids and fetal programming part 1 outcomes, Nat. Rev. Endocrinol. 10 (7) (2014) 391-402.

[5] E. Zambrano, C. Guzman, G.L. Rodriguez-Gonzalez, M. Durand-Carbajal, P.W. Nathanielsz, Fetal programming of sexual development and reproductive function, Mol. Cell Endocrinol. 382 (1) (2014) 538-549.

[6] M.N. Manojlović-Stojanoski, V. Milošević, Prenatal glucocorticoids: short-term benefits and long-term risks, in: X. Qian (Ed.), Glucocorticoids-New Recognition of Our Familiar Friend, In Tech-Open Access Publisher, 2012.

[7] S.G. Matthews, Antenatal glucocorticoids and programming of the developing CNS, Pediatr. Res. 47 (3) (2000) 291-300.

[8] R. Pascual, M. Valencia, S. Larrea, C. Bustamante, Single course of antenatal betamethasone produces delayed changes in morphology and calbindin-D28k expression in a rat's cerebellar Purkinje cells, Acta Neurobiol. Exp. (Wars) 74 (4) (2014) 415-423

[9] R.C. Piffer, P.C. Garcia, D.C. Gerardin, W.G. Kempinas, O.C. Pereira, Semen parameters, fertility and testosterone levels in male rats exposed prenatally to betamethasone, Reprod. Fertil. Dev. 21 (5) (2009) 634-639.

[10] R.C. Piffer, P.C. Garcia, O.C. Pereira, Adult partner preference and sexual behavior of male rats exposed prenatally to betamethasone, Physiol. Behav. $98(1-2)(2009)$ 163-167.

[11] E.d., Souza, S., Kobayashi, M.d.J., Simões, L., Camano, L., Kulay Júnior, Ação da Betametasona em Ratas Prenhes: Impacto sobre os Níveis de Corticosterona e Glândulas Adrenais Maternas e Fetais, Revista Brasileira de Ginecologia e Obstetrícia 23 (10) (2001) 667-673.

[12] Y. Su, J. Bi, V.M. Pulgar, J. Figueroa, M. Chappell, J.C. Rose, Antenatal glucocorticoid treatment alters $\mathrm{Na}+$ uptake in renal proximal tubule cells from adult offspring in a sex-specific manner, Am. J. Physiol. Renal. Physiol. 308 (11) (2015) F1268-75.

[13] A.J. Drake, L. Liu, D. Kerrigan, R.R. Meehan, J.R. Seckl, Multigenerational programming in the glucocorticoid programmed rat is associated with generation-specific and parent of origin effects, Epigenetics 6 (11) (2011) 1334-1343.

[14] C. Rabadan-Diehl, P. Nathanielsz, From Mice to Men: research models of developmental programming, J. Dev. Orig. Health. Dis. 4 (1) (2013) 3-9.

[15] M.P. Hardy, H.B. Gao, Q. Dong, R. Ge, Q. Wang, W.R. Chai, X. Feng, C. Sottas, Stress hormone and male reproductive function, Cell Tissue Res. 322 (1) (2005) 147-153.

[16] I.L. Ward, J. Weisz, Differential-effects of maternal stress on circulating levels of corticosterone, progesterone, and testosterone in male and female rat fetuses and their mothers, Endocrinology 114 (5) (1984) 1635-1644.

[17] K.C. Page, C.M. Sottas, M.P. Hardy, Prenatal exposure to dexamethasone alters leydig cell steroidogenic capacity in immature and adult rats, J. Androl. 22 (6) (2001) 973-980

[18] P. Corbier, D.A. Edwards, J. Roffi, The neonatal testosterone surge: a comparative study, Arch. Int. Physiol. Biochim. Biophys. 100 (2) (1992) 127-131.

[19] A.S.a.S. Cupp, M.K., Embryonic Sertoli Cell Differentiation, in: M.K.a.C. Skinner, M.D. (Ed.), Sertoli Cell Biology, Elsevier Science (2005), pp. 43-70.

[20] F. Gogan, A. Slama, B. Bizzini-Koutznetzova, F. Dray, C. Kordon, Importance of perinatal testosterone in sexual differentiation in the male rat, J. Endocrinol. 91 (1) (1981) 75-79

[21] L.A. Mack, D.C. Lay, S.D. Eicher, A.K. Johnson, B.T. Richert, E.A. Pajor, Growth and reproductive development of male piglets are more vulnerable to midgestation maternal stress than that of female piglets, J. Anim. Sci. 92 (2) (2014) 530-548

[22] C.S. Borges, A.F.M.G. Dias, P.V. Silva, J.L. Rosa, M.T. Guerra, R.F. Silva, L.R.A. Kiguti, A.S. Pupo, W.G. Kempinas, Long-term adverse effects on reproductive function in male rats exposed prenatally to the glucocorticoid betamethasone, Toxicology (2016), Press, 1-9.
[23] O.C. Pereira, R.C. Piffer, Puberty installation and adrenergic response of seminal vesicle from rats exposed prenatally to hydrocortisone, Life Sci. 77 (12) (2005) 1381-1390.

[24] O.C.M. Pereira, A.C. Arena, F. Yasuhara, W.G. Kempinas, Effects of prenatal hydrocortisone acetate exposure on fertility and sexual behavior in male rats, Regul. Toxicol. Pharm. 38 (1) (2003) 36-42.

[25] R.M. Parker, Testing for reproductive toxicity, in: R.D. Hood (Ed.), Developmental and Reproductive Toxicology: a Practical Approach, CRC Press, 2006, pp. 472-474

[26] G.L. Foley, Overview of male reproductive pathology, Toxicol. Pathol. 29 (1) (2001) 49-63.

[27] F.C. Toledo, J.E. Perobelli, F.P.C. Pedrosa, J.A. Anselmo-Franci, W.D.G. Kempinas, In utero protein restriction causes growth delay and alters sperm parameters in adult male rats, Reprod. Biol. Endocrin. 9 (2011).

[28] Y. Clermont, S.C. Harvey, Duration of the cycle of the seminiferous epithelium of normal, hypophysectomized and hypophysectomized-hormone treated albino rats, Endocrinology 76 (1965) 80-89.

[29] A. Crudo, S. Petropoulos, V.G. Moisiadis, M. Iqbal, A. Kostaki, Z. Machnes, M. Szyf, S.G. Matthews, Prenatal synthetic glucocorticoid treatment changes dna methylation states in male organ systems: multigenerational effects, Endocrinology 153 (7) (2012) 3269-3283.

[30] T. Braun, D.M. Sloboda, B. Tutschek, T. Harder, J.R. Challis, J.W. Dudenhausen, A. Plagemann, W. Henrich, Fetal and neonatal outcomes after term and preterm delivery following betamethasone administration, Int. J. Gynaecol. Obstet. 130 (1) (2015) 64-69.

[31] S. Melching-Kollmuss, K.C. Fussell, R. Buesen, M. Dammann, S. Schneider, H. Tennekes, B. van Ravenzwaay, Anti-androgenicity can only be evaluated using a weight of evidence approach, Regul. Toxicol. Pharm. 68 (1) (2014) 175-192.

[32] C.E. Bertram, M.A. Hanson, Prenatal programming of postnatal endocrine responses by glucocorticoids, Reproduction 124 (4) (2002) 459-467.

[33] I. Mangelsdorf, J. Buschmann, B. Orthen, Some aspects relating to the evaluation of the effects of chemicals on male fertility, Regul. Toxicol. Pharmacol. 37 (3) (2003) 356-369.

[34] H. Wang, L.L. Yang, Y.F. Hu, B.W. Wang, Y.Y. Huang, C. Zhang, Y.H. Chen, D.X. Xu, Maternal LPS exposure during pregnancy impairs testicular development, steroidogenesis and spermatogenesis in male offspring, PLoS One 9 (9) (2014) e106786

[35] K.L. Franko, A.J. Forhead, A.L. Fowden, Differential effects of prenatal stress and glucocorticoid administration on postnatal growth and glucose metabolism in rats, J. Endocrinol. 204 (3) (2010) 319-329.

[36] L.L. Woods, Maternal glucocorticoids and prenatal programming of hypertension, Am. J. Physiol. Regul. Integr. Comp. Physiol. 291 (4) (2006) R1069-75

[37] T.L. Carvalho, S.O. Petenusci, A.L. Favaretto, W.G. Kempinas, Morphometric and biochemical evaluation of rat prostate and seminal vesicle following chemical sympathectomy with guanethidine, Arch. Int. Physiol. Biochim. 98 (5) (1990) 225-230.

[38] G.R.H. Klinefelter, R.A., Toxicology of the Male Excurrent Ducts and Accessory Sex Glands, in: K. K.S. (Ed.), Reproductive and Developmental Toxicology (1998), pp. 553-592.

[39] T.L. Lamanocarvalho, A.L.V. Favaretto, S.O. Petenusci, W.G. Kempinas, Prepubertal development of rat prostate and seminal-vesicle following chemical sympathectomy with guanethidine, Braz. J. Med. Biol. Res. 26 (6) (1993) 639-646

[40] J. Barthelemy, A. Adeeko, B. Robaire, D.G. Cyr, In utero exposure to tributyltin alters the expression of E-cadherin and localization of claudin-1 in intercellular junctions of the rat ventral prostate, Mol. Reprod. Dev. 74 (4) (2007) 455-467

[41] X.Y. Zhao, P.J. Malloy, A.V. Krishnan, S. Swami, N.M. Navone, D.M. Peehl, D. Feldman, Glucocorticoids can promote androgen-independent growth of prostate cancer cells through a mutated androgen receptor (vol 6, pg 703, 2000), Nat. Med. 6 (8) (2000) (939-939).

[42] E. Sasso-Cerri, P.S. Cerri, Morphological evidences indicate that the interference of cimetidine on the peritubular components is responsible for detachment and apoptosis of sertoli cells, Reprod. Biol. Endocrin. 6 (2008).

[43] R. Brehm, M. Zeiler, C. Ruttinger, K. Herde, M. Kibschull, E. Winterhager, K. Willecke, F. Guillou, C. Lecureuil, K. Steger, L. Konrad, K. Biermann, K. Failing M. Bergmann, A sertoli cell-specific knockout of connexin43 prevents initiation of spermatogenesis, Am. J. Pathol. 171 (1) (2007) 19-31.

[44] G.M. Kidder, D.G. Cyr, Roles of Connexins in Testis Development and Spermatogenesis, Semin Cell Dev Biol, 2016.

[45] M.S. Risley, I.P. Tan, C. Roy, J.C. Saez, Cell- age- and stage-dependent distribution of connexin43 gap junctions in testes, J. Cell Sci. 103 (Pt 1) (1992) 81-96.

[46] W.A. Roscoe, K.J. Barr, A.A. Mhawi, D.K. Pomerantz, G.M. Kidder, Failure of spermatogenesis in mice lacking connexin43, Biol. Reprod. 65 (3) (2001) 829-838.

[47] S. Sridharan, L. Simon, D.D. Meling, D.G. Cyr, D.E. Gutstein, G.I. Fishman, F. Guillou, P.S. Cooke, Proliferation of adult sertoli cells following conditional knockout of the Gap junctional protein GJA1 (connexin 43) in mice, Biol. Reprod. 76 (5) (2007) 804-812.

[48] K.J. Schimenti, S.K. Feuer, L.B. Griffin, N.R. Graham, C.A. Bovet, S. Hartford, J. Pendola, C. Lessard, J.C. Schimenti, J.O. Ward, AKAP9 is essential for spermatogenesis and sertoli cell maturation in mice, Genetics 194 (2) (2013) (447-+.). 
[49] M. Gregory, C.N. Kahiri, K.J. Barr, C.E. Smith, L. Hermo, D.G. Cyr, G.M. Kidder, Male reproductive system defects and subfertility in a mutant mouse model of oculodentodigital dysplasia, Int. J. Androl. 34 (6 Pt 2) (2011) e630-41.

[50] D.L. Chapman, D.J. Wolgemuth, Expression of proliferating cell nuclear antigen in the mouse germ line and surrounding somatic cells suggests both proliferation-dependent and -independent modes of function, Int. J. Dev. Biol. 38 (3) (1994) 491-497.

[51] S. Schlatt, G.F. Weinbauer, Immunohistochemical localization of proliferating cell nuclear antigen as a tool to study cell proliferation in rodent and primate testes, Int. J. Androl. 17 (4) (1994) 214-222.

[52] P.A. Hall, D.A. Levison, A.L. Woods, C.C. Yu, D.B. Kellock, J.A. Watkins, D.M. Barnes, C.E. Gillett, R. Camplejohn, R. Dover, et al., Proliferating cell nuclear antigen (PCNA) immunolocalization in paraffin sections: an index of cell proliferation with evidence of deregulated expression in some neoplasms, J. Pathol. 162 (4) (1990) 285-294.

[53] B. Kurowicka, G.J. Dietrich, G. Kotwica, Effect of neonatal or adult heat acclimation on testicular and epididymal morphometry and sperm production in rats, Reprod. Biol. 15 (1) (2015) 1-8.

[54] L.D.E. Russell, R.A., Sinha-Hikim, A.P., Clegg, E.D., in: C.R. Press (Ed.), Histological and Histopathological Evaluation of the Testis, Montreal, 1990, pp. 201-202.

[55] R.P. Amann, Detection of alterations in testicular and epididymal function in laboratory animals, Environ. Health Perspect. 70 (1986) 149-158. 